\title{
PERANCANGAN SISTEM MANAJEMEN RESTORAN DENGAN APLIKASI PEMESANAN RESTORAN BERBASIS MOBILE DALAM JARINGAN LOKAL
}

\author{
Manggala Raka Perkasa. ${ }^{1)}$,Rinta Kridalukmana. ${ }^{2)}$, Eko Didik Widianto. ${ }^{2)}$ \\ Program Studi Sistem Komputer, Fakultas Teknik, Universitas Diponegoro \\ Jalan Prof. Sudharto, Tembalang, Semarang, Indonesia
}

\begin{abstract}
In modern times, like today, the role of software or applications that run on top of the platform is very important. This is because almost all of the work done by the people, made by the software or application. Applications can be used to assist in the processing of data and upload the final report. Data recorded previously processed by the paper can be recorded and processed by the application so that more efficiently.Development of an information systemin this study using the method of waterfall. Waterfall model consist of: requirements, design, implementation, testing and maintenance. For the start of the design, developer need to observations or interviews to determine the needs of the system that being developed. Application developed using the framework Codeigniter. System Management Restaurant build for help uses that has restaurant to manage activity in there like order menu, processing menu in kitchen, make invoice for custumer, and generate report of finance. This application can be expected to help user in process data efficiently so thet improve wuality of restaurant in terms of service and time. This system has a 5 user that consisting of waiters, chef, cashiers, manager, owner which every user has different privilege. System management restaurant developed using web-based programming which support in mode client server and uses MySQL as a database management storage.
\end{abstract}

Keywords: Waterfall, Codeigniter, Web Base Language, MySQL

\section{PENDAHULUAN}

Perkembangan bisnis yang terjadi dewasa ini tidak terlepas dari peran teknologi.Salah satu manfaat penggunaan teknologi tersebut adalah kemampuannya dalam mengakomodir hampir seluruh informasi penting dari perusahaan kepada pelanggan, pemasok, dan karyawan. Akan tetapisering juga ditemukan perusahaan maupun organisasi yang masih menggunakan cara bisnis tradisional dalam menjalankan dan mengelola usaha mereka. Cara bisnis tradisional ini dianggap lambat, baik dalam pengolahan data, pemrosesan data, maupun setiap terjadi perubahan data, karena setiap data atau informasi harus diperbaiki secara manual.Cara ini cenderung tidak cocok apabila dijalankan di suatu perusahaan atau organisasi yang sedang berkembang karena memiliki tingkat efektifitas yang rendah.Sehingga adanya teknologi sangat dibutuhkan untuk menggantikan peran bisnis tradisional menuju arah yang lebih baik dengan mengedepankan aspek efektifitas dan efisiensi ${ }^{[1]}$.

Aplikasi yang akan dibahas pada penelitian ini adalah aplikasi manajemen restoran. Aplikasi ini menawarkan kemudahan dalam pengelolaan data pesanan secara realtime, mencatat transaksi yang dilakukan oleh pelanggan,serta pengolahan data keuangan (penjualan, pemasukan tambahan, dan pengeluaran). Bahasa pemrogaman yang digunakan dalam penelitian adalah bahasa pemrograman berbasis web. Hal tersebut dikarenakan pemrogaman berbasis web mendukung mode server client. Pada sisi server menggunakan PHP dan
HTML sebagai bahasa pemrogaman, sedangkan pada sisi client menggunakan PHP dan javascript untuk dapat mengakses data di server secara realtime. Perancangan sistem ini mengadaptasi program solis, yaitu software restoran, sistem manajemen restoran terintegrasi, yang dapat digunakan di semua jenis restoran. Sistem dapat disesuaikan dengan kebutuhan setiap restoran, untuk menyediakan layanan yang lebih baik kepada para pelanggan dan kendali yang lebih handal kepada para pengelola restoran.

Untuk menghindari pembahasan yang meluas, maka dalam tugas akhir ini ditetapkan batasan masalah, yang dibahas pada tugas akhir ini hanya meliputi perancangan sistem menggunakan bahasa pemrograman berbasis web dimana pada sisi server menggunakan HTML dan PHP sedangkan di sisi klien menggunakan PHP dan javascript. Sistem juga dirancang menggunakan framework codeigniter ${ }^{[5]}$ dengan MySQL sebagai basis penyimpanan data. Selain itu sistem hanya bisa dijalankan apabile device ataupun computer berada di jaringan yang sama atau sudah terdaftar oleh sistem.

\section{METODOLOGI PENELITIAN}

Terdapat beberapa metodologi yang dapat digunakan dalam proses pengembangan sebuah perangkat lunak. Aplikasi Sistem Manajemen Resto ini dirancang menggunakan metodologi pengembangan yang diadopsi dari metodologi waterfall $^{[2]}$. Metodologi waterfall dipilih karena proses pengembangannya dilakukan secara bertahap sehingga tidak terfokus pada tahapan tertentu. Gambar dibawah ini menunjukan model metodologi yang digunakan untuk mengembangkan aplikasi.

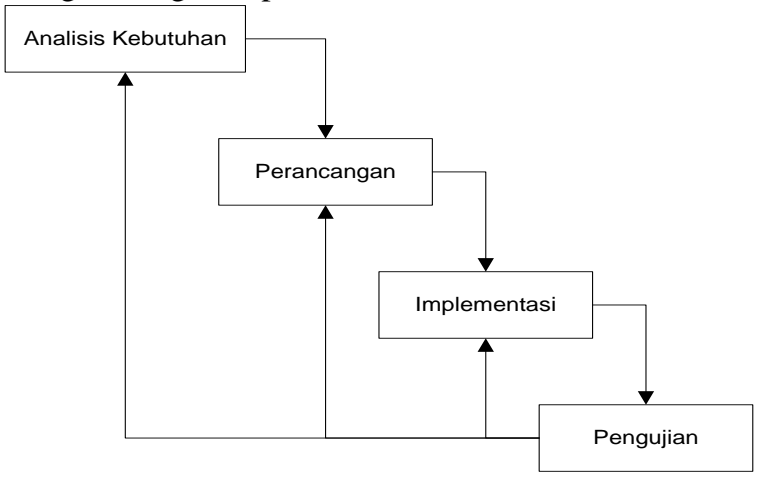

Gambar 1 Metodologi pengembangan yang diadopsi dari metologi waterfall

Pada tahap analisis kebutuhan, dilakukan wawancara dengan pemilik usaha yang telah menggunakan sistem restoran modern untuk mengetahui bagaimana proses bisnis berjalan. Hal itu dilakukan dengan mengamati dan melakukan observasi kebutuhan terhadap restoran tersebut.Dari hasil 
observasi dapat diketahui komponen apa saja yang dibutuhkan dalam membangun sistem terinteregrasi yang tidak hanya mampu mencatat aktivitas transaksional tetapi juga mengolah data pesanan pelanggan. Sistem ini diharapkan mampu meningkatkan kualitas servis dari segi efektivitas dan ketepatan waktu, sehingga akan berdampak pada meningkatnya kepuasan konsumen.

Sistem akan dikembangkan menjadi aplikasi berbasis web dan mobile. Sistem manajemen restoran pada server menggunakan platform windows 7 sebagai sistem operasinya dan diakses melalui web browser, sedangkan perangkat mobile menggunakan sistem operasi android dengan versi kitkat untuk mengakses sistem yang ada pada server. Web server dibutuhkan untuk menjalankan aplikasi tersebut.Sistem akan dijalankan melalui jaringan LAN yang sudah ditentukan. Sistem ini memerlukan access point sebagai media penghubung antara perangkat mobile dengan server.Sistem juga harus diinstal pada komputer yang bertindak sebagai server, kemudian diakses menggunakan 2 perangkat mobile olehpelayan dan koki. Gambar 2 menunjukkan arsitektur sistem yang menjelaskan bagaimana sistem bekerja.

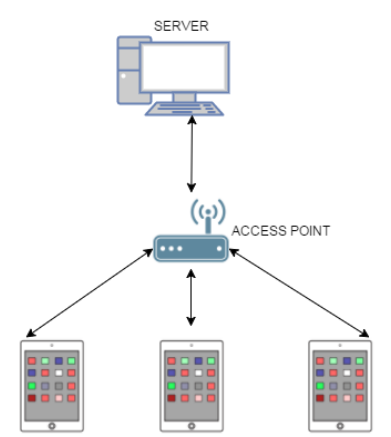

Gambar 2 arsitektur sistem

Dalam mendesain sistem dilakukan dengan pemodelan menggunakan $\mathrm{UML}^{[6]}$ melalui diagram use case, diagram aktifitas dan desain $\mathrm{ERD}^{[3]}$ untuk menggambarkan diagram relasi.Pemodelan UML digunakan untuk mengembangkan detail fungsi yang dibutuhkan oleh sistem sebelum memulai penulisan kode sedangkan desain ERD digunakan untuk megetahui atribut, entitas, hubungan antar entitas dalam basis data. Kesalahan yang terjadi pada saat melakukan pemodelan akan lebih mudah diperbaiki dan dianalisis pada design sistem dibandingkan dengan menulis langsung bahasa pemrograman.

Penelitian ini menghasilkan sistem restoran yang mampu mengolah data keuangan secara terintegrasi dengan sistem pemesanan.Dengan adanya sistem ini diharapkan dapat mengganti pengolahan data secara tradisional menjadi lebih terstruktur sehingga mampu meningkatkan kualitas pelayanan kepada konsumen, serta memudahkan pemilik usaha dalam mengawasi perkembangan usahanya ${ }^{[2]}$.

\section{PERANCANGAN SISTEM}

\section{A. ANALISIS KEBUTUHAN}

Penyusunan analisis kebutuhan bertujuan untuk mengurangi risiko sistem gagal dikembangkan.Kegagalan pengembangan sistem umumnya terjadi karena sistem tidak memenuhi kebutuhan pengguna atau sistem tidak sesuai dengan proses bisnis yang berjalan. Studi kelayakan perlu dilakukan dalam penyusunan analisis kebutuhan untuk menghindari risiko tersebut.Studi kelayakan dapat dilakukan dengan cara wawancara, observasi dan membaca dokumen. Hasil analisis kebutuhan berupa dokumen system requirements specifications (srs).

\section{Kondisi awal}

Proses wawancara dan observasi memberikan gambaran kondisi yang terjadi dilapangan. Pada proses pemesanan, terdapat beberapa aktivitas yang harus dilakukan, yaitu proses pemesanan dengan diawali permintaan pemesanan oleh pelanggan kepada pelayan, kemudian pelayan akan memasukan atau mengirimkan data pesanan ke dalam sistem. Data pesanan yang tersimpan di sistem secara otomatis akan tampil di timeline kerja koki sehingga koki bisa segera membuat pesanan.

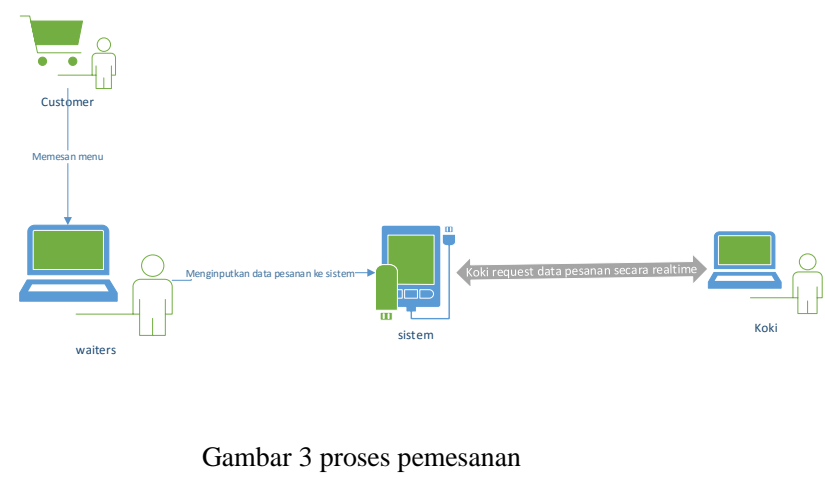

Proses berikutnya adalah mengirimkan pesanan ke meja pelanggan. Koki wajib memberikan konfirmasi pesanan selesai apabila pesanan sudah dibuat dan siap dihidangkan.Data konfirmasi tersebut akan ditampilkan sebagai notifikasi pada device pelayan sehingga pelayan siap mengambil pesanan yang ada di dapur untuk dikirimkan ke meja pelanggan.

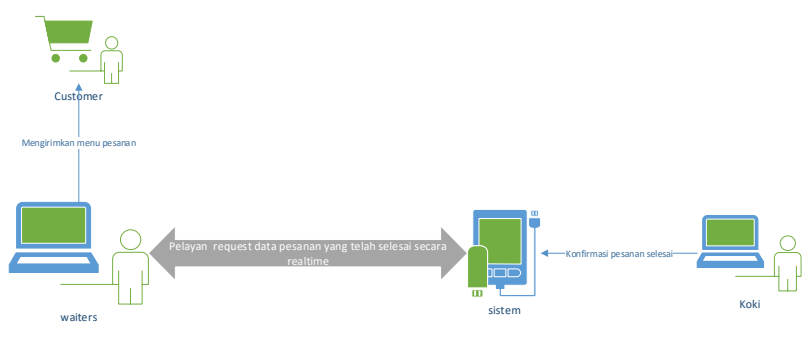

Gambar 4 kirim pesanan

Berdasarkan proses tersebut maka dapat dianalisis data yang diolah sebelum sistem dikembangkan, yaitunama pelanggan, tempat yang digunakan, detail pesanan, harga menu, bahan baku, waktu tunggu, estimasi waktu pesanan selesai.Pembuatan srs dapat dilakukan setelah data yang dikumpulkan pada kondisi awal sudah cukup menjelaskan keadaan sebelum sistem dikembangkan.

\section{Deskripsi umum}

Deskripsi umum sistem diperlukan untuk menjelaskan perspektif produk akhir hasil 
pengembangan, fungsi produk yang diharapkan untuk berjalan, kelompok pengguna, lingkungan pengoperasian serta lingkungan pengguna yang akan menggunakan sistem. Pengguna yang menggunakan sistem ini terdiri dari 5 jenis, yaitu: pengguna owner, pengguna manager, pengguna waiter dan pengguna koki, pengguna. Semua pengguna tersebut memiliki privilege atau hak akses masing-masing dalam menggunakan sistem. Tabel 1 menunjukan penjelasan untuk tiap pengguna.

Tabel 1 deskripsi pengguna

\begin{tabular}{|c|c|c|}
\hline No & $\begin{array}{c}\text { Hak } \\
\text { Akses }\end{array}$ & Deskripsi \\
\hline 1 & Manager & $\begin{array}{l}\text { Pengguna manajer adalah pengguna } \\
\text { yang ditunjuk untuk melakukan peran } \\
\text { sebagai manajer dalam restoran. } \\
\text { Manajer dalam sistem ini mempunyai } \\
\text { tugas dalam mengawasi kegiatan } \\
\text { operasional dan keuangan }\end{array}$ \\
\hline 2 & $\begin{array}{l}\text { Owner } \\
\text { (Pemilik) }\end{array}$ & $\begin{array}{l}\text { Pengguna owner adalah pemilik dari } \\
\text { restoran yang memiliki peran untuk } \\
\text { mendaftarkan user ke dalam sistem, } \\
\text { memberikan hak akses pada user dan } \\
\text { juga melihat record keseluruhan dari } \\
\text { sistem. }\end{array}$ \\
\hline 3 & pelayan & $\begin{array}{l}\text { Pengguna waiter adalah pengguna } \\
\text { yang ditunjuk untuk melakukan peran } \\
\text { sebagai waiter atau pelayan. Waiter } \\
\text { bertugas melakukan pencatatan data } \\
\text { untuk setiap pesanan yang diterima } \\
\text { dari pelanggan. Selain itu waiter juga } \\
\text { bertugas untuk mengantarkan } \\
\text { pesanan yang sudah selesai dibuat ke } \\
\text { meja pelanggan dan membersihkan } \\
\text { meja ketika pelanggan sudah } \\
\text { meninggalkan tempat. }\end{array}$ \\
\hline 4 & koki & $\begin{array}{l}\text { Pengguna koki adalah pengguna yang } \\
\text { ditunjuk untuk melakukan peran } \\
\text { sebagai koki. Koki bertugas } \\
\text { mengolah data yang diterima dari } \\
\text { waiter dan juga melakukan } \\
\text { permintaan kepada manajer ketika } \\
\text { kebutuhan dapur habis. }\end{array}$ \\
\hline 5 & kasir & $\begin{array}{l}\text { Pengguna kasir adalah pengguna } \\
\text { yang ditunjuk untuk melakukan } \\
\text { peran sebagai kasir. Kasir bertugas } \\
\text { untuk memproses transaksi } \\
\text { pembayaran. Selain itu kasir juga } \\
\text { menyediakan layanan informasi } \\
\text { tempat mana saja yang tersedia atau } \\
\text { bisa digunakan. }\end{array}$ \\
\hline
\end{tabular}

B. DESAIN SISTEM

Berikut ini pemodelan yang digunakan dalam perancangan sistem:

\section{Diagram Use Case}

Diagram use case dibuat berdasarkan skenario yang dilakukan pengguna ketika menggunakan fungsi sistem. Diagram use case terlihat pada Gambar 5

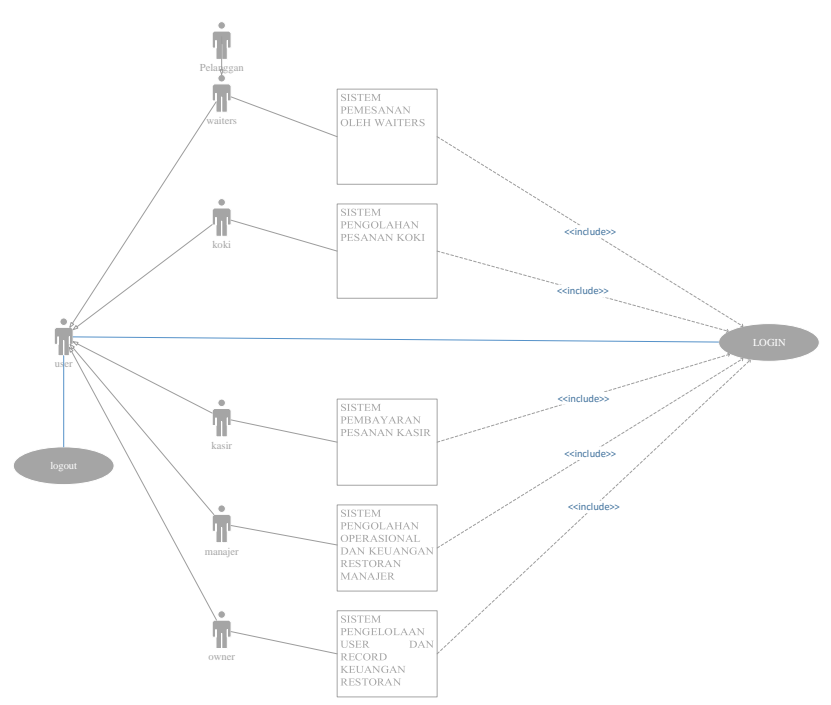

Gambar 5 Diagram use case previlege user

Pemodelan diagram use case menunjukan bahwa sistem memiliki 5 aktor yang menggunakan sistem dimana tiap aktor memiliki tugas dan fungsi sistem yang berbeda sesuai dengan privilege yang dimiliki.

\section{Diagram Aktivitas}

Diagram aktivitas berguna untuk memberikan perspektif mengenai proses bisnis yang dilakukan.

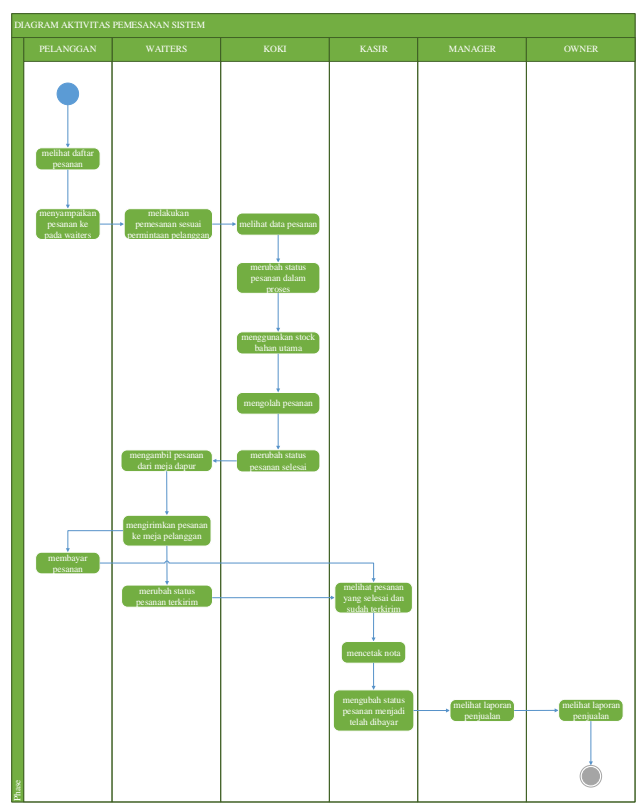

Gambar 6 Diagram aktivitas sistem

Gambar 6 menunjukan diagram aktivitas sistem yang akan dikembangkan. Proses sistem ini dimulai ketika pelanggan memesan menu dan berakhir ketika pelanggan membayar menu yang dipesan.

\section{Diagram Relasi}

Diagram relasi menunjukan hubungan antara entitas dan atribut antar tabel database.Tujuan dari diagram adalah menjelaskan hubungan antara entitas yang telah ditentukan. Relasi yang digambarkan dapat diperjelas dengan menambahkan informasi kardinalitas antara 
entitas.Berikut ini adalah diagram yang digambarkan berdasarkan atribut yang ada.

a. relasi entitas user

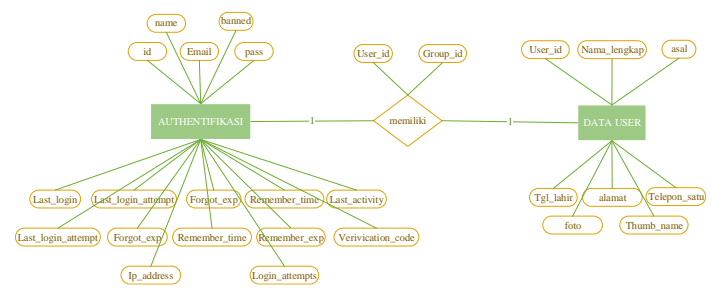

Gambar 7 diagram relasi authentifikasi dengan data user

b. relasi entitas daftarmenu

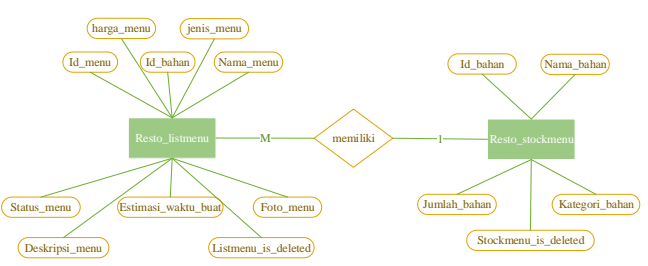

Gambar 8 diagram relasi resto_listmenu dan resto_stockbahan

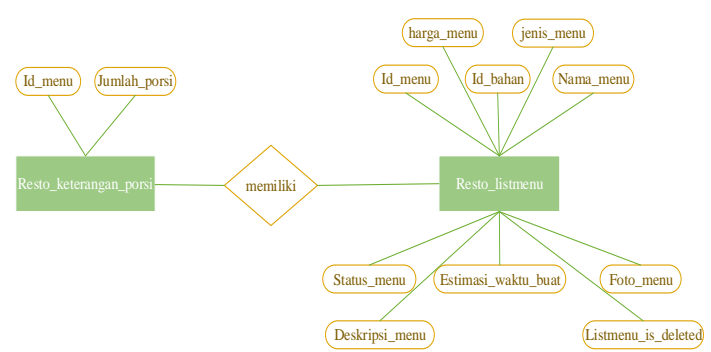

gambar9 diagram relasi resto_keterangan_porsi dan resto_listmenu

c. relasi entitas data pesanan

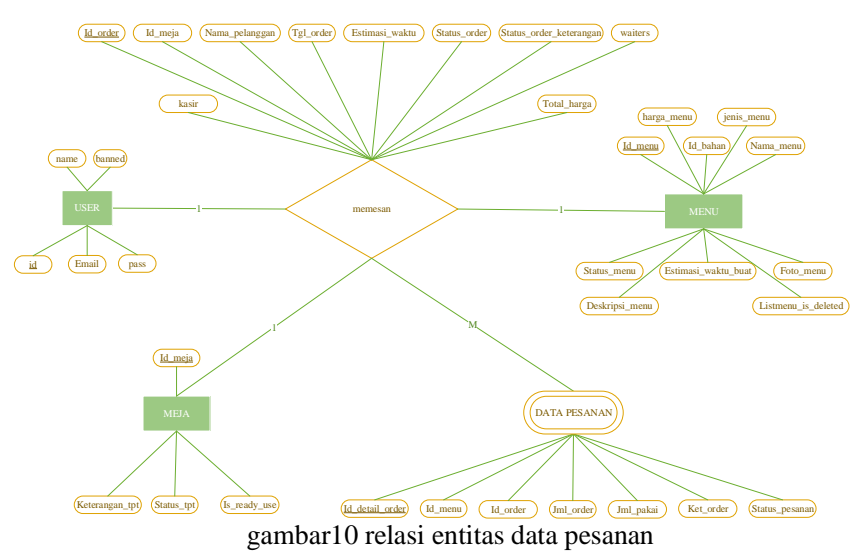

d. deskripsi tabel basis data

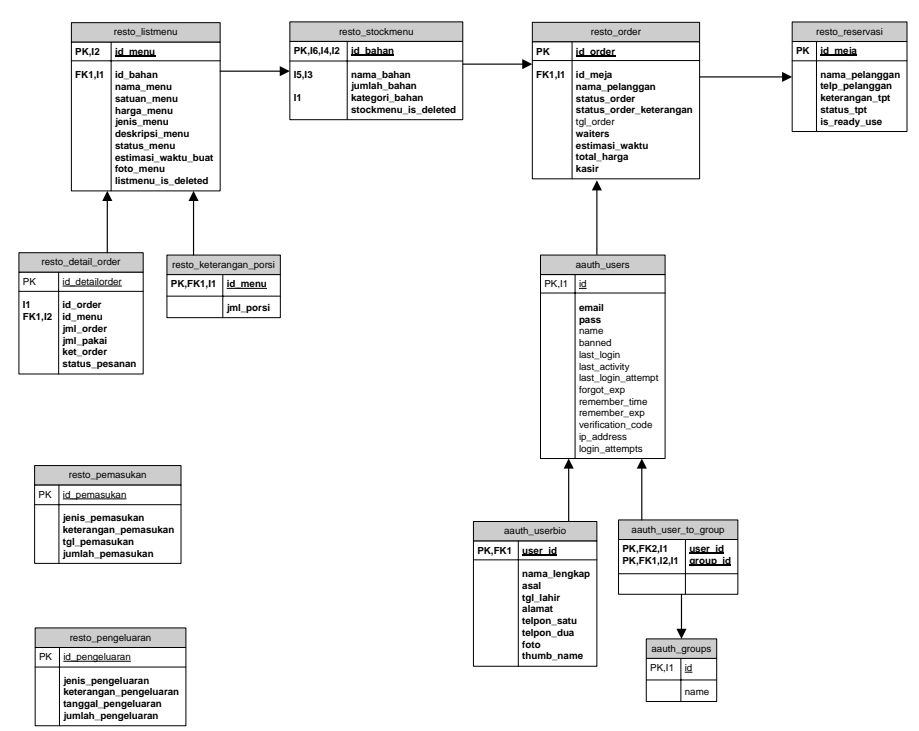

gambar11 diagram relasi antar basis data

\section{IMPLEMENTASI DAN PENGUJIAN SISTEM}

\section{A. Tahap Pembuatan}

Pembuatan sistem dilakukan dengan mendesign user interface yang akan digunakan oleh sistem, menjabarkan aktor yang terlibat dalam sistem ini untuk kemudian membuat fungsi yang dibutuhkan agar sesuai dengan hak akses yang dimiliki user. Pada pembuatan sistem ini digunakan perangkat keras dan perangkat lunak dengan spesifikasi sebagai berikut:

1. Perangkat Keras

a. Personal Computer (PC) atau Laptop Perangkat keras yang digunakan dalam penelitian ini yairu sebuah komputer dengan spesifikasi sebagai berikut:Prosesor Intel Core i5; memori RAM 8,00 GB; harddisk 1TB; monitor LCD 24 Inchi.

b. 1 buah mouse

c. 1 buah keyboard

2. Perangkat Lunak

a. Microsoft Windows 7

b. XAMPP

c. Corel Draw X6

d. Sublime

B. Hasil Pengujian

Pengujian integrasi dilakukan untuk mengetahui apakah setiap fungsi yang dimiliki sistem mampu saling terhubung untuk melakukan pekerjaan utama.Pengujian dilakukan karena kesalahan dalam sistem mungkin terjadi walaupun masing - masing fungsi telah diuji. Kesalahan seperti itu umumnya terjadi karena fungsi yang ada tidak terhubung atau tidak memiliki batasan yang sama dengan fungsi lainnya. Pengguna mengeksekusi banyak fungsi dalam melakukan pekerjaannya.Hubungan antar fungsi tersebut adalah bentuk integrasi unit.Skenario buatan atau simulasi pekerjaan dilakukan untuk menjalankan pengujian integrasi. Skenario yang dilakukan pada pengujian ini adalah sebagai berikut : 


\section{Petugas waiters memasukan data pemesanan}

Pelanggan harus melakukan pemesanan melalui waiters. Pada pengujian ini waiters dengan nama mengkii akan melakukan pemesanan atas nama rosalita dan tempat lokasi pemesanan berada di lesehan 5 yang ditunjukan Gambar 12 .

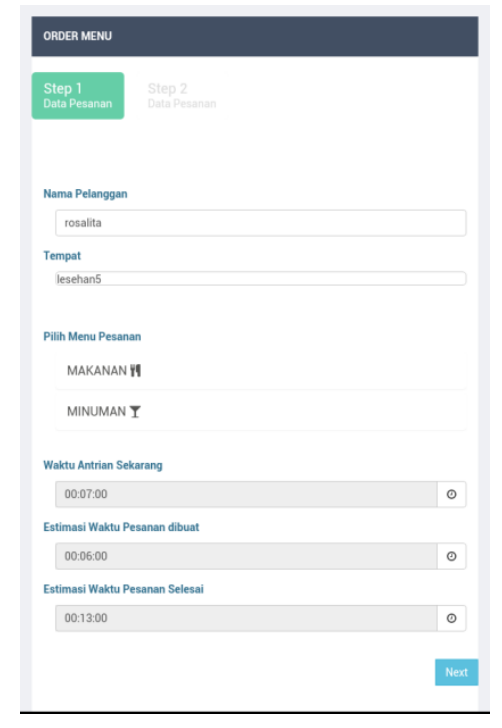

Gambar 12 Pengujian membuat data pesanan baru

Pada langkah satu dalam membuat data pesanan baru, pengguna wajib mengisi field nama pelanggan, memilih tempat yang digunakan pelanggan, dan memilih menu yang dipesan. Apabila tidak mengisi field nama pelanggan dan memilih tempat dengan benar maka akan muncul peringatan dan tidak bisa melanjutkan ke tahap berikutnya, ditunjukan pada Gambar 13 .

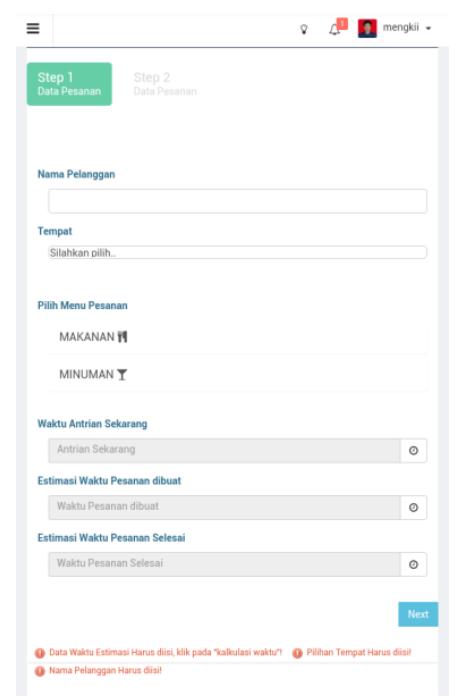

Gambar 13Pengujian peringatan kesalahan pada form pesanan baru

Langkah berikutnya adalah pengguna bisa membaca data pemesanan sementara dan memastikan semua data pemesanan telah memenuhi syarat sebelum data disimpan ke dalam basis data.Gambar 14 menunjukan data pemesanan sementara.

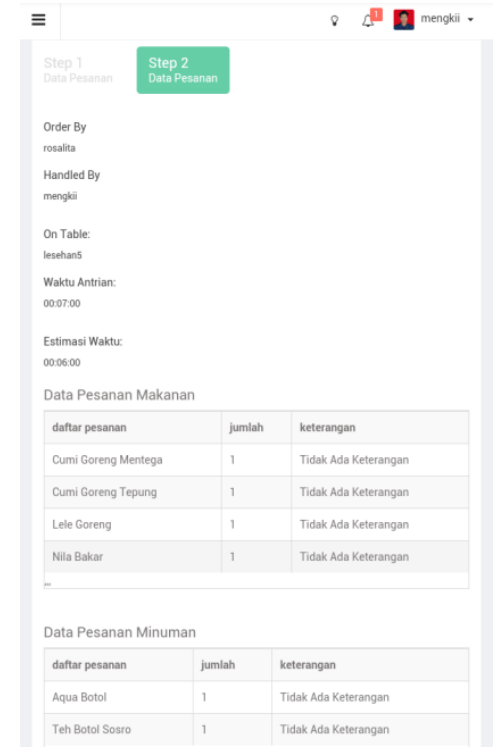

Gambar 14 Pengujian data pemesanan sementara

Tekan tombol tambahkan untuk menyimpan data pesanan ke dalam basis data. Data pesanan yang tersimpan di basis data nantinya akan muncul secara realtime di timeline kerja pengguna dengan hak akses koki.

\section{Petugas koki mengolah data pesanan}

Data pesanan yang masuk di timeline kerja koki berasal dari pengguna dengan hak akses waiters.Timeline pesanan akan menampilkan data pesanan yang akan diolah secara realtime. Pengujian dilakukan dengan menekan menu kelola pesanan, kemudian akan muncul timeline pesanan seperti Gambar 15 .

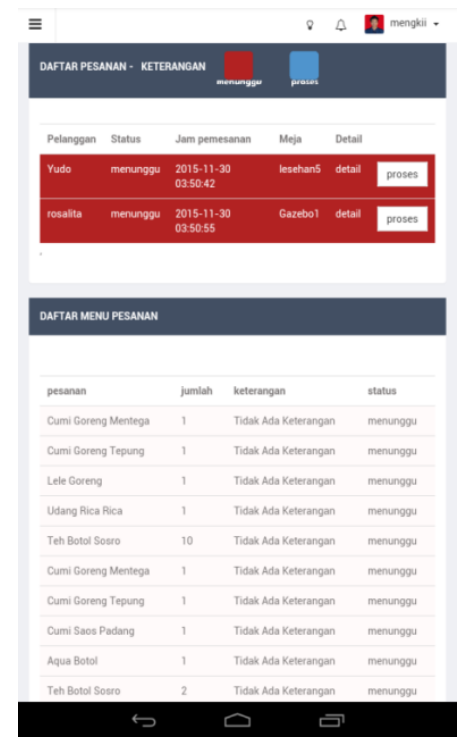

Gambar 15 Pengujian timeline pesanan menunggu

Warna merah pada timeline pesanan menunjukan pesanan dalam proses menunggu. Ketika pesanan dengan status menunggu atau baris warna merah diproses nantinyaakan berganti warna menjadi biru yang menandakan bahwa pesanan sedang diproses. Gambar16 menunjukan timeline pesanan yang sudah diproses oleh koki. 


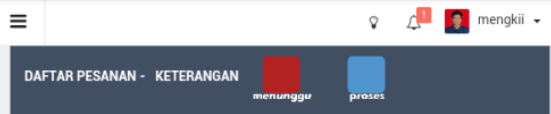

[5]

Febrian, Jack.. Kamus Komputer dan Teknologi Informasi. Bandung, INFORMATIKA, 2006.

Hartono, Jogiyanto. Analisis \& Desain Sistem Informasi Pendekatitan Terstruktur Tereoriri dan Praktek Aplikasi Bisnis. Yogyakarta : Penerbit ANDI, 2005.

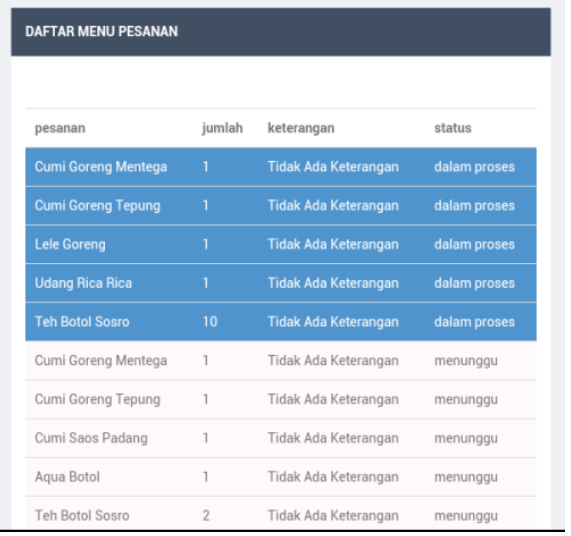

Gambar 16 Pengujian timeline pesanan dalam proses

Jika pesanan telah selesai dibuat, koki harus menekan tombol finish.Popup konfirmasi akan muncul ketika tombol finish ditekan dan mengubah status pesanan menjadi selesai. Apabila berhasil maka pesanan yang sudah selesai tidak akan ditampilkan di timeline kerja koki dan pesanan yang sudah selesai bisa segera diambil oleh waiters di meja dapur untuk segera diantarkan kepada pelanggan.

Pengujian sistem dilakukan dengan menggunakan metode black-box. Pengujian ditekankan pada fungsionalitas dari sistem itu sendiri. Berikut adalah Tabel 2 yang berisi serangkaian pengujian fungsi pada sistem.

Tabel 2 Pengujian keseluruhan sistem

\begin{tabular}{|l|l|l|c|}
\hline \multicolumn{1}{|c|}{$\begin{array}{c}\text { Nama } \\
\text { Pengujian }\end{array}$} & $\begin{array}{c}\text { Bentuk } \\
\text { Pengujian }\end{array}$ & $\begin{array}{l}\text { Hasil yang } \\
\text { Diharapkan }\end{array}$ & $\begin{array}{c}\text { Hasil } \\
\text { Pengujian }\end{array}$ \\
\hline $\begin{array}{l}\text { Pengujian } \\
\text { halaman } \\
\text { utama } \\
\text { sistem }\end{array}$ & $\begin{array}{l}\text { Setelah } \\
\text { login } \\
\text { ditekan }\end{array}$ & $\begin{array}{l}\text { Tampilan } \\
\text { halaman } \\
\text { awal }\end{array}$ & Berhasil \\
\hline $\begin{array}{l}\text { Pengujian } \\
\text { pesan menu }\end{array}$ & $\begin{array}{l}\text { Menekan } \\
\text { tombol } \\
\text { pesan } \\
\text { menu }\end{array}$ & $\begin{array}{l}\text { Muncul } \\
\text { notifikasi } \\
\text { pesanan } \\
\text { berhasil } \\
\text { ditambahkan }\end{array}$ & Berhasil \\
\hline $\begin{array}{l}\text { Pengujian } \\
\text { timelinekoki }\end{array}$ & $\begin{array}{l}\text { Menekan } \\
\text { tombol } \\
\text { kelola } \\
\text { daftar } \\
\text { pesanan }\end{array}$ & $\begin{array}{l}\text { Tampilan } \\
\text { halaman } \\
\text { timeline } \\
\text { koki }\end{array}$ & Berhasil \\
\hline $\begin{array}{l}\text { Pengujian } \\
\text { logout }\end{array}$ & $\begin{array}{l}\text { Menekan } \\
\text { tombol } \\
\text { logout }\end{array}$ & $\begin{array}{l}\text { Kembali ke } \\
\text { tampilan } \\
\text { halaman } \\
\text { login }\end{array}$ & Berhasil \\
\hline
\end{tabular}

\section{PENUTUP}

A. Kesimpulan

Kesimpulan yang dapat diambil dari penelitian Aplikasi Manajemen Restoran dengan Pemesanan Menu Berbasis Mobile yang telah dilakukan adalah sebagai berikut ini :

1. Pengguna aplikasi terdiri dari waiters, koki, kasir, manajer, owner dimana tiap pengguna memiliki fitur yang berbedabeda tergantung privilege yang diatur oleh sistem.

2. Aplikasi dengan basis web dapat mengolah data pesanan dari pelanggan, mengolah stock barang, menu makanan dan minuman yang tersedia, mengolah data tagihan pembayaran, dan mengelola pengguna berdasarkan hak akses yang ditentukan.

3. Aplikasi basis mobile dapat melakukan pencatatan pesanan dari pelanggan, memberikan informasi tempat yang tersedia di restoran.

4. Aplikasi dengan basis web dapat menampilkan keuangan restoran yang terdiri dari data pemasukan dan data pengeluaran restoran.

5. Aplikasi bisa digunakan apabila device maupun komputer berada di jaringan yang sama.

\section{B. Saran}

Saran yang dapat diambil dari Tugas Akhir ini adalah sebagai berikut:

1. Sistem manajemen restoran memiliki banyak aspek untuk dikembangkan seperti integrasi dengan sistem manajemen karyawan.

2. Fitur absensi karyawan dan gaji karyawan pada sistem manajemen karyawan belum bisa diimplementasikan karena dibutuhkan perancangan dan pengembangan sistem yang berbeda.

3. Perlu dilakukan penelitian lebih lanjut agar fitur - fitur pada aplikasi dapat ditambah dan lebih responsife.

4. Perlu dilakukan penelitian lebih lanjut agar aplikasi dapat melakukan backup data secara otomatis saat aplikasi mengalami gangguan.

\section{DAFTAR PUSTAKA}

[1] Anisyah. Analisa dan Desain Sistem Informasi. Yogyakarta : Penerbit ANDI, 2000.

[2] C.J., Date. Pengenalan Sistem Basis Data (diterjemahkan oleh Carley Tanya). Jakarta: PT. Indeks Group Gramedia, 2004.

[3] Connoly, T., \& Begg, C. (2002). Database Systems: A Pratical Approach to Design, Implementation, and Management, edisi ke-3. Harlow: Addison-Wesley.

[4] Dhanta, Rizky. Pengantar Ilmu Komputer. Surabaya : INDAH, 2009.

[5] Febrian, Jack.. Kamus Komputer dan Teknologi Informasi. Bandung : INFORMATIKA, 2006.

[6] Hartono, Jogiyanto. Analisis \& Desain Sistem Informasi Pendekatan Terstruktur Teori dan Praktek Aplikasi Bisnis. Yogyakarta : Penerbit ANDI, 2005. 